\title{
ethic@ \\ NORMATIVIDADE SEMÂNTICA E NATURALISMO: UMA CONSIDERAÇÃO DAS DIMENSÕES SEMÂNTICA E INTERPRETATIVA DE PERSPECTIVAS NORMATIVAS
}

\author{
SEMANTIC NORMATIVITY AND NATURALISM: \\ A CONSIDERATION OF THE SEMANTIC AND INTERPRETIVE \\ DIMENSIONS OF NORMATIVE PERSPECTIVES
}

\author{
ROBERTO BARROS ${ }^{1}$ \\ (UFPA/Brasil)
}

\begin{abstract}
RESUMO
O presente artigo tem por finalidade problematizar o caráter interpretativo de perspectivas normativas, tendo como pressuposto que o conteúdo enunciativo da norma é sempre compreendido mediante uma perspectiva projetiva e objetivante por parte de quem a formula, e de uma atitude compreensiva e doadora de significado por parte daquele que busca interpretá-la. Tal abordagem pressupõe, portanto, uma consideração de aspectos estruturantes atuantes em formulações normativas, mas também de fatores interpretativos quando uma perspectiva normativa é problematizada. Com isso tem-se por meta evidenciar a impossibilidade de fundamentação última de normas e então argumentar em favor dos aspectos positivos deste ponto de vista.
\end{abstract}

Palavras-chave: Normatividade; Semântica; Naturalismo; Interpretação.

\begin{abstract}
The purpose of this article is to problematize the interpretative character of normative perspectives, assuming that the enunciative content of the norm is always understood through a projective and objective perspective on the part of those who formulate it, and with a comprehensive and meaningful attitude on the part of one who seeks to interpret it. Such approach presupposes, therefore, a consideration of structural aspects acting in normative formulations, but also of interpretive factors when a normative perspective is problematized. The intention is to highlight the impossibility of providing the ultimate foundation for standards and then to argue in favor of the positive aspects of this point of view.
\end{abstract}

Keywords: Normativity; Semantics; Naturalism; Interpretation.

\section{Introdução temática}

Em um amplo período do pensamento ocidental uma das questões centrais com respeito à normatividade envolveu o tema da precisa formulação dos enunciados normativos e disso decorreu uma concepção por 
longo tempo dominante no campo de reflexão sobre o tema, segundo a qual, a acuidade lógico-racional dos enunciados seria suficiente para lhes proporcionar validade e fundamentação objetivas. Uma consideração mais pausada dos pressupostos desta perspectiva remete imediatamente a noções elementares da racionalidade ocidental, tal como a de que haveria a possibilidade, por meio do uso lógico do intelecto, de formular e compreender princípios estáveis e objetivos com respeito a coisas singulares, em outras palavras, de que seria possível racionalmente indicar suas características essenciais e objetivas e com isso compreendê-las e transmiti-las seguramente. Por conseguinte, a tradição racionalista desde os eleatas e em grande parte assimilada por Platão partiu do pressuposto de que a determinação do princípio enunciador (Platão, 1980 a, 484 a, p. 277) rigoroso e universal com respeito às coisas poderia caracterizar o próprio conhecimento, indicando com isso um critério lógico de verdade, que susteria a validade do saber frente posicionamentos meramente intuitivos e não universalizantes ${ }^{2}$. Segundo esta perspectiva, a razão seria capaz de, sem outra mediação que não a lógica, ou reproduzir a forma arquetípica de compreensão objetiva das coisas ou fatos particulares, ou de Ihes enunciar as sínteses definidoras e objetivantes (Angioni, 1997, p. 214). Esses pressupostos marcaram decisivamente a concepção de conhecimento no pensamento ocidental e se fizeram presentes em muitas teorias da objetividade, que continuaram a cogitar a possibilidade transmissão de conhecimentos assentes de modo unívoco, por meio de padrões lógicos de formulação e de inteligibilidade. Atualmente, outras linhas de interpretação tendem a compreender a questão comunicacional para além do "transport model of comunication" (Schneider, 2012, p. 138) e é a partir delas e da identificação de uma postura normativa já presente no esforço intelectual de conceituação - caracterizando uma expansão do domínio especulativo para o prático (Gert, 2004, p. 7) - que consideraremos o tema proposto. Com isso, a dicotomia que propicia a diferenciação entre conhecimento e opinião será reconsiderada e reposicionada no âmbito da problematização de questões de interrelação de interpretações sígnicas entre os sujeitos racionais, mais especificamente funcionando como princípio balizador de problematizações éticas e normativas com pretensões de validade intersubjetiva. Neste sentido, o pressuposto primeiro de que haveria a possibilidade de racionalmente formular enunciados normativos cuja validade e objetividade fossem garantidos pela coerência lógico-racional dos mesmos, aspecto que então Ihes serviria de fundamento e de legitimação dado o caráter de necessidade que a racionalidade Ihes atribuiria, será colocado em questão, assim como posicionamentos enfáticos relativos à 
normatividade prescritiva e à positividade jurídica baseadas em uma interpretação essencialista da norma.

É impossível aqui retomar todos os detalhes da concepção hilemórfica da enunciação, dando voz a todos os seus agentes e múltiplas perspectivas, assim como enunciar seus problemas, para então esclarecer a opção pela via da interpretação sígnica de enunciados. Todavia, de forma sintética e tomando como coerente o posicionamento contemporâneo de Quine em sua análise crítica e não essencialista da ação enunciativa, que indica que o uso de enunciações linguísticas como significantes é possível mesmo quando pensada uma relação outra, "sem favorecer um reino de entidades chamadas significados" (Quine, 2011, p. 25), tomaremos uma posição de afastamento com respeito à tradição acima mencionada, dado que prescindimos da perspectiva de fundamentação última de enunciados normativos. Com isso, o que se deseja propor aqui não é formular uma nova teoria fundante da normatividade, mas, precisamente, interpretá-la segundo um direcionamento deflacionado de toda inclinação essencialista, para com isso defender o pressuposto de que nenhum enunciado normativo é considerado, com ou sem anuência, sem âmbitos ou dimensões interpretativas diretamente ligadas a interesses práticos ou valorativos e que, a partir deste aspecto, uma consideração que não leva em considerações fatores transversais relativos tanto à formulação quanto à interpretação da regra, tende a recair ou permanecer presa em um essencialismo normativo abstrato de difícil justificação efetiva. O problema de investigação a ser aqui colocado e analisado é, portanto, buscar ressaltar dimensões que compõem os contextos interpretativos da normatividade como meio a partir do qual, perspectivas normativas possam ser pensadas segundo outros pressupostos que não associados a essencialismos ou formalismos fundantes.

\section{A intransponibilidade dos processos interpretativos}

Partindo aqui do pressuposto segundo o qual formulações e interpretações ocorrem sempre norteadas por aspectos balizadores e estruturantes, por padrões e requisitos (Kiesewetter, 2019, p. 3). Propomos então, a partir disso, dividir os fatores interpretativos relativos à normatividade inicialmente em duas grandes categorias não reducionistas, de modo primeiramente operativo e as indicando como interconectadas no que concerne tanto a formulações quanto a interpretações normativas: a dos fatores internos e a dos fatores externos. Os Fatores internos dividiremos ainda em dois subgrupos, também interrelacionados. 0 dos aspectos fisiológicos e o dos aspectos psicológicos. O primeiro diz respeito 
a interação de mecanismos orgânicos e neurológicos conhecidos e atuantes na formulação das regularidades identitárias que fazemos uso devido necessidades orgânicas (Maturana, H e Varela, F, 1987, p. 23), tomadas aqui como passíveis de indicar a existência de certa forma de organização tanto de nossas percepções de mundo, mas também de nossos modos de compreendê-lo ${ }^{3}$. O âmbito psicológico, por sua vez, é tomado aqui como atuante nas manifestações simbólicas da nossa experiência de vida e indissoluvelmente ligado ao fisiológico4. Neste sentido, os fatores internos abarcariam tanto aspectos lógicos, sob o ponto de vista do estabelecimento de relações tanto instintivas quanto causais, considerada a atuação de aspectos não linearmente lógicos naquilo que convencionamos chamar de pensamento consciente (Damásio, 2000, p. 45). Este seria o ponto de intercessão entre estes dois fatores, pois é reconhecido hoje, segundo uma perspectiva evolucionista, que traços psicológicos tidos por conscientes reagem a partir de motivações orgânicas tidas como não conscientes, o que pressupõe a necessidade de revisão da suposição da superioridade do pensamento racional ou consciente sobre fatores instintivos e, deste modo, da autonomia e do princípio de primazia do pensamento racional em nossas tomadas de decisão e ações de compreensão.

Os fatores externos, por outro lado, podem ser compreendidos como aspectos históricos, sociais, econômicos, culturais e morais, que também estão diretamente relacionados com os fatores psicológicos, todavia em uma relação significativa outra, pois os segundos não se deixam interpretar plenamente a partir dos primeiros, haja vista as múltiplas contextualidades valorativas ${ }^{5}$. Uma aproximação entre ambos pode ser indicada na categorização indicada por Iain Brassington, referentes a questões de primeira e de segunda ordem no que se refere a debates morais. Segundo o autor, questões de primeira ordem consistiriam naquelas que tendem a considerar ações permitidas e admiradas como verdadeiras (we have to think that a claim to the effect that an action is permissible, admirable, or whatever, is true) e as de segunda ordem adviriam do desdobramento da pressuposição de que a consideração da pretensão moral como verdadeira apresenta uma tendência normativa (we have to believe that the truth of our moral claim is going to have some sort of normative clout) (2007, p. $1)^{6}$. A diferenciação de Brassington possibilita que compreendamos a interseção entre padrões mentais, concebidos a partir de uma determinação orgânica e demandas externas, que mesmo ligadas às primeiras não podem ser reduzidas unicamente a elas. Neste caso, a necessidade do verdadeiro, em sua significação normativo-prescritiva, demonstra tanto uma inclinação psíquica quanto uma intencionalidade prática, o que se contrapõe às tendências essencialistas ou fundantes de interpretação da norma. 
A partir destas delimitações é então possível, sob o ponto de vista da análise de enunciados, mencionar um aspecto primordial concernente à normatividade, tal como ela é considerada aqui. $O$ de compreender que normas ou princípios prescritivos não podem ser confundidos com enunciados descritivos. Por conseguinte, a norma é aqui interpretada como uma projeção valorativa de possibilidades e por isso possui certo grau de inconsistência (Corrêa, 2020 p. 44), proferida a partir de um enunciado formulado com pretensões práticas, mas também de objetividade (Davidson, 2006. P. 39), ao passo que o enunciado descritivo está comprometido com a representação de algo a partir de critérios de referencialidade aceitos com respeito ao referente (Nozick, 1993, p. 23).

Esses aspectos tornam extremamente problemática a hipótese da justificação última de normas pautadas no pressuposto de sua necessidade, ou seja, na pretensão de demonstração de sua validade objetiva e de consequente intransponibilidade (Brassington, 2007, p. 28). Tal pressuposto, que busca aplicar um critério de objetividade adotado nas ciências naturais, pautado por um pressuposto de confirmação experimental e não de necessidade prescritiva, não é realizável em problematizações normativas, dado que o processo de formulação dos enunciados é outro, como explicitaremos a seguir. Desse modo, uma proposição normativa, por exemplo, mesmo as menos disputáveis sob o ponto de vista valorativo, tais como "não matarás", ou "tenha consideração para com os outros", não apenas não podem ser confundidas com proposições descritivas, como demonstram comportar a projeção de uma perspectividade com pretensões objetivantes e futuras ${ }^{7}$, muito embora não possam ter aspiração real de possuírem o mesmo grau de assertividade de proposições descritivas, pois seus enunciados em nada alteram o fato de que muitos seres humanos continuam a matar outros seres humanos e a agir segundo cálculos individuais ou princípios subjetivos em detrimento a pressupostos universalizantes.

Consideramos então o fator projetivo presente na perspectiva de quem propõe ou fórmula uma norma, assim como os traços interpretativos/valorativos da confrontação com a norma proposta, como pontos nucleares de compreensão e de análise da perspectiva normativa, seja ela judicativa ou propositiva. A problematização da normatividade não pode perder de vista estes aspectos intrínsecos, pois nas relações entre o proponente da norma e aquele ao qual ela se direciona - por conseguinte entre norma e agente - não é possível mencionar nem um enunciado descritivo, tampouco um processo direto de assimilação decorrente do enunciado mas, antes, com respeito a ambos os casos, processos interpretativos de grande complexidade e que resultam em uma ampla 
variabilidade de possibilidades de compreensões da norma (Davidson, 2006, p. 51).

\section{A impossibilidade de determinação da totalidade dos pressupostos interpretativos}

Entretanto, a pretensão de indicar alguns princípios gerais do processo interpretativo não deve ser confundida com algum tipo de hipótese ou anseio de presumir algo como uma enumeração da totalidade dos aspectos envolvidos nele. Antes, trata-se de ressaltar a importância da sua inserção em considerações de perspectivas normativas, enquanto fator intransponível e, a partir disso, demonstrar as dificuldades de perspectivas normativas essencialistas ou fundamentalistas.

Neste sentido, desejamos indicar três pontos de análise: 1. Primeiramente o relativo ao conteúdo valorativo do pressuposto da verdade e à pretensão de validação deste, o que chamaremos de crença moral. A abordagem deste tema mobilizará uma perspectiva naturalistaevolucionista não reducionista ${ }^{8}$, portanto apartada de qualquer pressuposição realista ou metafísica de verdade, a partir da qual o pressuposto da existência objetiva da verdade é compreendido como padrão mental valorativo e fator de inteligibilidade de proveniência biológica. 2. O segundo ponto é o do aspecto semântico da normatividade, compreendida em uma perspectiva antirrealista e metafisicamente deflacionada, segundo a qual, a forma lógica é associada a uma estrutura argumentativa e não a conhecimento (Schneider, 2004, p. 145) ou delimitação de significado. 3. Por fim, o traço interpretativo envolvido na relação entre singularidade e norma, que imediatamente se instaura quando uma reflexão normativa ocorre ou é problematizada, seja pela perspectiva do formulador de uma norma, seja do ponto de vista daqueles a quem a norma é proposta.

\section{A crença moral}

Por crença moral entendemos aqui a inclinação de todo avaliador de se sentir preliminarmente convicto de que a avaliação que lhe parece convincente é verdadeira e justificável (Dall'agnol, 2020, p. 56). Desejamos interpretar tal inclinação inicialmente como tendência estruturante de nosso modo de pensar e de formular interpretações do mundo e que foi teoricamente assimilada por uma ampla tradição do pensamento ocidental na formulação de pressupostos de veracidade. Com isso deseja-se ressaltar que este pressuposto é considerado como um padrão cognitivo que o pensar 
traz consigo, indicando, porém, que apenas o fato de que o tenhamos inerentemente integrado à atuação mais elementar de nossos processos cognitivos, este dado não é suficiente para lhe conferir a solidez que intuitivamente somos inclinados a conferir a ele.

Segundo uma perspectiva histórica, a epistemologia dos antigos esteve envolvida ou com a defesa da existência efetiva e estável do conhecimento, ou com a negação de tal possibilidade. Foi o início da modernidade, marcado pela ascensão das ciências naturais e por suas perspectivas metodológicas, que colocou de forma central, para além do racionalismo, a questão das formas de justificação do conhecimento. Em Francis Bacon, mas decisivamente em Descartes e Kant, as questões relativas ao método e às possibilidades do conhecimento afastam-se de posições puramente especulativas e mantiveram nos seus horizontes as ciências naturais, mas também, paralelamente, a crítica do seu reducionismo, voltando-se assim para a questão de que papel desempenharia o sujeito racional na produção do conhecimento científico. Com o decisivo passo dado por Kant com respeito à questão do conhecimento na sua Crítica da razão pura, foram indicadas possibilidades e limites do conhecimento humano, ao mesmo tempo que o filósofo acreditava ter colocado fim à tendência cética defendida pelos empiristas. O seu esforço de descrição do funcionamento dos aparatos sensório e cognitivo significaram um passo decisivo para a filosofia moderna no que se refere as suas possibilidades argumentativas e formas de produção e de justificação do conhecimento. Com Kant estabeleceu-se o pressuposto do conhecimento como sendo produto da relação entre um sujeito perceptivo e racional e um mundo apreendido por este mesmo sujeito mediante suas estruturas perceptivas e cognitivas. Com o giro copernicano, o sujeito racional, foi então decisivamente colocado como núcleo imprescindível da produção do conhecimento sobre o mundo, todavia, não como aquele que apenas o interpreta, mas como aquele que determina as condições de inteligibilidade do mesmo ${ }^{9}$. Com diferentes variações, estes pressupostos foram mantidos pelos idealistas alemães até Hegel e que passaram a ser confrontados com os desafios e resultados das ciências experimentais no século XIX.

Uma nova orientação acerca da questão do conhecimento se faz presente na filosofia alemã a partir de Schopenhauer e de Nietzsche, os primeiros a mobilizarem a perspectiva naturalista não pautados por considerações unicamente afirmativas da racionalidade e que conectaram em consonância com a então emergente biologia no século XIX - corpo (organismo) e racionalidade, argumentando que padrões de compreensibilidade desta, tais como identidade, causalidade e verdade, 
responderiam a necessidades orgânicas e não a qualidades objetivas das coisas ${ }^{10}$. Suas revisões críticas da epistemologia kantiana e dos seus diferentes pressupostos, indicaram que a necessidade de estabilidade dos objetos de consideração humana seria, original e primeiramente, orgânica - portanto não determinantemente racional e que isso seria decisivo para a estrutura interpretativa do intelecto na sua construção representacional do mundo (Nietzsche, FW/GC § 110, KSA 3, p. 469). A repercussão deste novo posicionamento foi significativa, decisivamente no que diz respeito à necessidade de reconsideração das fronteiras do conhecimento humano e indicaram um novo campo de investigação no que se refere à influência de fatores biológicos nos padrões estruturantes do intelecto. Esta tendência foi determinante para o surgimento da teoria evolucionista do conhecimento, com respeito a qual podemos citar diferentes, mas aproximadas interpretações (Pöltner, 1993, p. 63), como as de Herbert Spencer e Karl Popper, passando por Konrad Lorenz, Gerhard Vollmer, Rupert Riedl, Quine e que, nos dias atuais, é defendida por evolucionistas como Gerald Edelmann e neurocientistas como António Damásio, Maturana e Varela, mas também por filósofos como John Searle e John Denett.

Estes pontos de distinção entre a abordagem contemporânea e a da tradição são determinantes para o fato de a contemporaneidade ter em grande parte abdicado da pretensão de fundamentação substantiva ou definitiva do conhecimento e se direcionado prioritariamente à problematização de novos critérios para a sua justificação. Considerado o goro da pretensão de fundamentação definitiva do conhecimento (Abel, 2020, p. 190), a filosofia contemporânea também não mais pressupõe um embasamento definitivo para a normatividade, mas passou a buscar justificações (Pfordten, 2018, p. 8) a partir de outros pressupostos e superando as noções de ceticismo ou relativismo moral problematizadas pela tradição.

Um ponto de partida da nova consideração desta nova perspectiva pode ser mencionado como a problematização dos filósofos da linguagem da distinção entre enunciados referenciais e enunciados valorativos, ou seja, entre fatos e valores (Coop, 2001, p. 12). Wittgenstein, instado pela problematização de alguns pontos da perspectiva referencial de Frege, foi um dos que primeiros contemporâneos a chamar atenção para este aspecto no que se refere à moral e à ética. No seu Tractatus Logico-philosophicus ele se empenha em mostrar a ausência de sentido de proposições éticas para além das possibilidades de formulação das mesmas. Partindo dos pressupostos da infinitude da lógica contraposta aos limites das formas de enunciação tautológico-referencial, o filósofo compreende serem infinitas as possibilidades de formulações de proposições e enunciados, mas que isso 
não significa que estes necessariamente possuam referencialidade efetiva com respeito a algum estado de coisas (Sachverhalten), pois apenas as possibilidades de concatenação lógica das proposições não podem ser indicadas como critério de verdade (TLP § 5.55), mas tão-somente de sentido, compreendido que as continuidades lógicas não necessariamente implicam ou carecem de referencialidade. Para o filósofo, a linguagem produz afigurações (Abbildungen) do mundo, que podem ser corretas (richtig) ou falsas (TLP § 2.17), mas isso no sentido da referência a um estado de coisas ou efetividade (TLP § 2.223) e não à sua estrutura lógica, pois esta pode produzir afigurações falsas (TLP § 2. 173), subentendido que "uma imagem verdadeira a priori não existe" (TLP § 2.224).

Este aspecto permite Wittgenstein afirmar que formulações éticas e estéticas estariam inseridas nesta forma de enunciação e seriam a mesma coisa no que concerne à significação referencial de suas proposições. Neste sentido, especificamente com relação à ética em sua pretensão universalista, suas proposições seriam sem sentido (unsinnig) sob o ponto de vista referencial, muito embora não em significado. Desse modo, o equívoco com respeito à lógica da linguagem repousa para Wittgenstein na carência de compreensão das formas de seu uso em nossas relações figurativas com o mundo. A filosofia metafísica oblitera a diferenciação entre organização lógica de pensamentos, que é intransponível (TLP § 3.031), e a diferença entre o modo de relação destes pensamentos e a sua relação a posteriori com a efetividade. Ela transpõe os limites da lógica entendida como teoria das formas e se enclausura no contexto do uso linguístico autoevidente. Isso significa deixar de perceber que proposições simplesmente nomeiam as coisas, elas não às dizem (TLP § 3.221) e que no contexto do uso linguístico, as possibilidades de nomeação são infinitas. Desse modo, a maioria das proposições e questões referentes à filosofia não são falsas, mas sem sentido (TLP § 4.003). Elas não possuem nenhum outro significado além daquele que lhes cabe no interior do uso lógico da linguagem e por isso não podem pretender consistir em enunciados verdadeiros tais como as proposições das ciências. Nesta via Wittgenstein toca em um ponto central para a discussão acerca da normatividade, qual seja, o de que convicções valorativas ou normativas não possuem garantia implícita de que sejam verdadeiras ou necessárias e, ainda, que o processo de consideração das mesmas não se dá de forma direta, mas é mediado por uma ação interpretativa intransponível, que não pode ser associada a nenhuma pretensão de validade objetiva e é neste sentido que, nas Investigações filosóficas, Wittgenstein chamou a atenção para a diferença entre acreditar seguir uma regra e segui-la efetivamente, evidenciando assim as dificuldades de justificação de uma regra prescritiva, mesmo 
considerando-se a possível acessão com respeito à mesma ${ }^{11}$. 0 ponto de vista de Wittgenstein nos possibiliza compreender os problemas da ausência de significação referencial de aspectos valorativos envolvidos nas tentativas de justificação de uma perspectiva normativa proposta e de como as mesmas não podem ser consideradas como presumivelmente possuindo algum critério de verdade inerente. Com isso é possível também compreender que a regra moral é usualmente justificada, seguida ou recusada, de modo primeiramente intuitivo e que mesmo pressupostos interpretativos e valorativos posteriores não podem oferecer um critério de pertinência efetivamente estabelecido ${ }^{12}$. É neste sentido que podemos falar de crenças morais, cuja atitude racional pode ser interpretada como irracionais no funcionamento (Gert, 2004, p. 6) ${ }^{13}$ e que são intransponivelmente atuantes nas bases de toda tentativa de fundamentação de uma prescrição moral, partindo-se do pressuposto que posicionamentos morais não são formulados a partir de critérios objetivos efetivos ${ }^{14}$, mas de valorações relativas entendidas enquanto tal e com significativo sentido pragmático (Corrêa, 2020, p.35).

Todavia, é necessário acentuar que neste ponto específico o critério da referencialidade não é mobilizado em um sentido reducionista ou realista, ou seja, pressupondo a possibilidade de um referencial enquanto justificativa última, mas apenas enquanto instância a partir da qual nós possamos elaborar critérios qualificadores (Davidson, 2006, p. 43). Isto significa que noções como as de identidade, causalidade sequencial, substância, espaço e tempo, são interpretadas aqui enquanto critérios mentais regulares, determinantemente atuantes na produção de nossas imagens do mundo exterior, insuperavelmente integrados às nossas formas de pensar e de falar, mas primeiramente produzidos a partir das condições de possibilidade advindas do desenvolvimento anatômico, de morfogênese e adaptativo do cérebro. A este respeito escreve Lorenz: "O "espetáculo" de nossos modos de pensamento e percepção, como causalidade, substância, qualidade. Tempo, e espaço são funções de uma organização neurosensória que esteve envolvida na tarefa da sobrevivência" (1973, p. 12).

A opção por uma interpretação evolucionista dos critérios de verdade e de fundamentação possibilita que possamos compreender os padrões estruturantes e intuitivos destas noções, enquanto fatores que influenciam na construção da confiança mais imediata desta forma de compreensão ${ }^{15} \mathrm{e}$ então distancia-las de qualquer pretensão de justificação para além de critérios predefinidos. A interpretação evolucionista dos nossos primeiros e mais intuitivos contatos com o mundo, expõe a significativa importância do desenvolvimento orgânico para o estabelecimento de nossas estruturas mentais, argumentando com isso em favor do seu enraizamento orgânico 
(Wuketits, 1990, p. 2), seu viés pragmático e não necessariamente cognitivo16. Desse modo, ela nos possibilita entender como esses padrões de inteligibilidade adquirem para nós um caráter de confiabilidade que, todavia, é, de forma primaz, intuitivo e sem nenhum vínculo demonstrável de determinação com a efetividade, a qual, por conseguinte, não pode ser reduzida a tais padrões. Por fim, a deflação metafísica da verdade e do conhecimento não necessariamente deve remeter a uma negação de possibilidade de ambos, mas à consideração de novas formas de consideralos. Tal perspectiva se direciona prioritariamente a compreender a estrutura fisio-psicológica das pressuposições de verdade de nossas avaliações morais e normativas, revelando que a confiabilidade que conferimos aos padrões intuitivos se origina da necessidade prática e de um longuíssimo uso que fizemos deles em estágios evolutivos anteriores (Haselton et al., 2009, p. 740). Desse modo, mesmo em face das suas limitações dedutivas ante questões complexas, elas podem ser extremamente úteis à compreensão da dimensão interpretativa de nossas perspectivas normativas.

\section{Semântica e normatividade}

Considerando-se então que nenhuma perspectiva normativa se deixa fundamentar de forma definitiva e ainda, que sua assimilação jamais se dá de forma unívoca pelos agentes que as formulam e interpretam, analisaremos aqui alguns aspectos relativos às formas de abordagem do traço semântico da norma e às possibilidades de justificação de perspectivas normativas dissociadas de pretensões deterministas.

Inicialmente é necessário ressaltar que a indicação de uma dimensão semântica da normatividade pressupõe também a negação do pressuposto de que alguma perspectiva ou pressuposição normativa possa possuir um fundo último e referenciável de justificação ${ }^{17}$. Em segundo lugar, é também aqui pressuposto que proposições normativas possuem tendências objetivantes que, apesar de se mostrarem praticamente incapazes de efetivação, não são intencionalmente superáveis e que isso, todavia, não deve significar um argumento contrário à amplitude das perspectivas normativas, mas a toda pretensão fundante de validação universal necessária de normas. Portanto, em terceiro lugar, desejamos ressaltar que a partir destes aspectos seria possível pressupor que proposições normativas não possam mais ser mencionadas ou concebidas com pretensões de validade substantiva, mas apenas como projeções prescritivas $^{18}$. 
Com respeito ao primeiro aspecto, a noção de fundamento pode, previamente a sua pressuposição, ser primeiramente compreendida como um padrão mental de crença significativa ${ }^{19}$ e não como aspecto de passível efetivação. Com efeito, como argumenta Quine a respeito de nossas generalizações relativas a conjuntos e tipos, estas apresentam uma série de paradoxos lógicos e, portanto, "definição de similaridade em termos de tipos é hesitante (halting), e definição de tipos em temos de similaridade é desconhecida (unknown)"(1969, p. 121). Usando exemplos do aprendizado humano, Quine argumenta em favor da existência de estágios primitivos (primitive stage of learning) e que "na maioria das vezes o processo é inconsciente (unconscious)" e comparável ao processo de aprendizado dos animais (1969, p. 122). O filósofo norte americano então indica a existência de um "em certo sentido inato elementar de similaridade (a standard of similarity is in some sense innate)", no sentido de uma anterior diferenciação de qualidades (prior spacing of qualities), sem o qual "todos os estímulos seriam igualmente semelhantes (alike) e igualmente diferentes (equally different) e ao qual deve ser relacionado também um "senso inato de similaridade", enquanto partes de nossa origem animal (animal birthright) (1969, p. 123). Este processo indutivo, constitutivo da expectação animal e da formação de hábitos, seria atuante no processo de aprendizado das palavras (1969, p. 125) e conferiria ao uso das mesmas, fundadas em uma ideia de causalidade por semelhança, uma "piedosa esperança" na "conclusão precipitada" (blossons into a foregone conclusion) responsável pela sua origem por similaridade causal. Em uma perspectiva evolucionista baseada em traços ligados aos genes, Quine busca mostrar a origem de nossas formas de separação e agregação em similaridades e tipos e as relações causais intuitivas, no que elas implicam, para, desse modo, argumentar com respeito as suas fragilidades e inadequações no que concerne à tipologia da pesquisa científica e em prol de como as primeiras podem ser consideradas insignificantes para a ciência com perspectivas teóricas. Essas, para ele, nem mesmo necessitam basear-se em modificações de tipologias intuitivas, podendo, portanto, consistir em teorias desenvolvidas sem antecedentes (1969, p. 128). Todavia, para Quine, isso não significa a superação das dificuldades da similaridade e da tipologia, mas pressupõe a necessidade de superação das formas elementares e de adoção de metodologias mais sofisticadas, pois:

Entre tipos teóricos e intuitivos, certamente o
teóricos são os desejados com o objetivo de definir
solubilidade (solubility) e outras disposições de interesse científico
(Quine, 1969, p. 131).


A reflexão de Quine sintetizada aqui é importante para a compreensão do grau de validade que generalizações podem alcançar. Isso não no sentido de defini-las, mas de compreender a limitação da pretensão intencional das mesmas ${ }^{20}$. No domínio científico, o grau de validade das generalizações e especulações causais é justificado não pelos seus pressupostos teóricos ou coerência intuitiva, mas primeiramente pelos resultados experimentais que alcançam, o que não é e, eventualmente jamais será, o caso de propostas normativas. Estas, antes, se pautam primeiramente em uma demanda prática não descritiva, mas primeiramente prescritiva e com isso não podem e nem necessitam pretender obter graus efetivos de objetividade transpostos das ciências, pois a via de formulação de ambas as formas argumentativas é significativamente diferente (Dall'agnol, p. 56).

Com efeito, pode-se mencionar aqui a interpretação de Noan Chomsky, que argumenta em favor de uma compreensão do pensar humano a partir dos mecanismos linguísticos da gramática. Para ele é necessário compreender que o uso não refletido (unknowledge and totally without awareness) das regras linguísticas pode consistir em um importante instrumento de consideração de nossas estruturas de pensamento, assim como dos significados que aferimos às coisas que mencionamos (Chomsky, 2006, p. 92). Com isso Chomsky indica ainda haver um aspecto semântico na interpretação das sentenças basilares com que produzimos e usamos, que ele denomina de "estrutura profunda", (deep structure) (p. 93), em diferenciação às estruturas superficiais (surface), "que se referem à representação das frases que constituem a expressão linguística e as categorias às quais estas frases pertencem" (Chomsky, 2006, p. 92).

Com a noção de estrutura profunda, Chomsky evidencia um ponto central para a análise da normatividade aqui proposta, qual seja, a da hipótese de que enunciados normativos possuem tanto uma estrutura lógica adequada às regras que estruturam a linguagem na qual eles são produzidos, mas também dimensões semânticas e interpretativas atuantes na determinação do significado (Chomsky, 2006, p. 97). Isso implica novamente em argumentos contrários a qualquer pretensão da existência de uma determinação final do significado e em favor do pressuposto da dimensão semântico-interpretativa destes que, a partir de critérios normativos não absolutos, podem ser tomados como estáveis.

Estrutura profunda fornece relações gramaticais de predição, modificação e assim por diante, que entre na determinação do significado. Por outro lado, parece que as questões de foco e pressuposto, tópico e comentário, o escopo da lógica, elementos e referência pronominal são determinados, pelo menos em parte, 
pela estrutura superficial. As regras que relacionam estruturas sintáticas e representações de significado não são de todo bem entendidas. De fato, a noção "representação do significado", ou "representação semântica" é, em si, altamente controversa. Não está claro nada disso, é possível distinguir nitidamente entre a contribuição da gramática para a determinação do significado das chamadas "considerações pragmáticas", questões de fato e crença e contexto do enunciado (Chomsky, 2006, p. 97).

\section{A dimensão interpretativa da normatividade}

Neste sentido, a questão das dimensões semântica e interpretativa de enunciados passa a ter uma posição central. Günter Abel, com efeito, apresenta uma muito sofisticada teoria da interpretação, enquanto aspecto intransponível da comunicação linguística e indica serem processos interpretativos traços basilares à reflexão normativa (Abel, 2020, p. 177). Partindo da posição wittgensteiniana segundo a qual quando seguimos regras nós as seguimos cegamente, Abel afirma que apenas quando esse cego seguir não acontece ou não há a capacidade de fazê-lo, ocorre um processo de interpretação do enunciado que não é aleatório, mas se dá a partir de um processo perspectivístico e que apresenta uma forma, muito embora não seja possível determiná-la em sua completude.

O mais importante âmbito da utilização de signos, o da efetivação de signos, é inapropriadamente descrito quando entendido como uma exegese, seguindo critérios preexistentes. A efetivação de signos realmente não ocorre sem regulação, mas sim "sem explicações", livre de exegese (Deutungslos), "sem critérios", portanto não criterial. Seguir uma regra exige não tanto a capacidade de explicar, mas a capacidade prática de seguir a regra (Abel, 2020, p. 129).

Abel associa à internalização de regras a um "saber-como" (Knowinghow), enquanto aspecto da assimilação prática da regra (2018, vol. 1, p. 501), a ponto de afirmar que "a sensibilidade para normas pode simultaneamente tornar-se nossa segunda natureza" (2018, p, 502). Entretanto ele diferencia essa internalização de uma assimilação mecânica de regras (tal como movimentos táticos no xadrez), em favor de uma efetivação interna da normatividade do "saber-como" (Vollzug-interne Normativität des Knowing-How), inerente, tanto, por exemplo, ao andar de bicicleta, ao falar ou pensar, portanto, uma normatividade processual interna, imanente e concreta (prozess-interne, immanente und konkrete 
Normativität), que seria também responsável pelas "condições de êxito (Gelingensanforderungen) de efetivações (Vollzüge) de práticas, processos, proceduras, indicações e mesmo de interpretações" (2018, p. 504).

A argumentação eurística de Abel, que compreende a impossibilidade proposicional de se indicar o que venha a ser o significado (Bedeutung) de um exitoso "saber-como" concreto, não verificável por um mundo linguística e sígnicamente independente (2018, p. 504) - portanto da inquirição da correta apreensão de sua expressão normativa - é importante para evidenciar a complexidade e mesmo impossibilidade da pretensão em determinar quais seriam os aspectos envolvidos situacionalmente na prática interpretativa da reflexão normativa. Abel nos mostra que os processos interpretativos inerentes a perspectivas normativas não são redutíveis a simples visões realistas ou referenciais e, a partir disso, nos evidencia a importância de indicar ou eliminar decisivamente aspectos a partir dos quais a normatividade é interpretada com graves reducionismos e, desse modo, torna possível recomendar a necessidade de reconsideração de padrões e pressupostos relativos à justificação de perspectividades normativas enquanto tarefa de nosso tempo e de seu horizonte teórico.

\section{Conclusão}

A argumentação desenvolvida até aqui visou prioritariamente apresentar argumentos divergentes das posições realistas ou fundacionistas da normatividade, pressupondo, todavia, ser a inclinação normativa uma característica humana insuperável e mesmo necessária. A perspectiva naturalista então mencionada objetivou argumentar que a normatização é parte constitutiva de nossa natureza orgânica, que se reflete em nossas atitudes intelectivas e, neste sentido, não é possível superá-la. Por conseguinte, a partir disso buscou-se demonstrar que refletir sobre perspectivas normativas a partir de novos pressupostos consiste em uma tarefa de primeira ordem de nosso tempo, contudo mediante uma perspectiva de justificação e não de fundamentação última da normatividade (Dall'agnol, 2020, p. 56). O direcionamento seguinte da abordagem foi buscar indicar os processos sígnicos-interpretativos inerentes às perspectivas normativas para, a partir desses pressupostos, evidenciar as dificuldades de interpretações realistas do significado e com isso indicar a necessidade de formulação de novos pressupostos de consideração e de justificação daquelas. Buscou-se também mostrar que, apartada da pretensão de validação universal ou de fundamentação última, a normatividade parece poder ser compreendida com ganhos no seu caráter perspectivístico, o que não apenas pode distanciá-la de tendências 
dogmatizantes ou autoritárias, como abrir novos âmbitos de debates propositivos a seu respeito. Com isso tinha-se em vista demonstrar que compreender a normatividade como uma característica da perspectividade simbólica humana, antes de colocar em questão o sentido de perspectivas normativas, poderia ser melhor compreendido como uma contribuição indicativa da necessidade de ampliação de possibilidades de reflexão sobre ela, do mesmo modo que sobre os sistemas normativos já propostos ou estabelecidos. Compreender a tendência normativa enquanto intencionalidade representativa (Bickhard, 2010, p. 27) abre possibilidades de reflexão sobre a abrangência efetiva de modelos e pressupostos representacionais utilizados no sentido de uma melhor compreensão de suas possibilidades, funções e alcance efetivos. 


\section{Notas}

${ }^{1}$ Professor da Universidade Federal do Pará (UFPA). Graduação em Filosofia pela UFPA, mestrado em Filosofia junto à UNICAMP e Doutorado em Filosofia pela Universidade Técnica de Berlim (TU-Berlin). Atualmente é Professor da FAFIL/PPGFIL UFPA, com atuação na área de filosofia contemporânea. ORCID-ID: https://orcid.org/0000-0001-6142-450X; e-mail: robertbarr@gmx.net

2 Vale indicar aqui que com respeito à lei, que o próprio Platão parece dar indicações de ter compreendido as dificuldades deste projeto e, após as considerações da problemática Ser e do não-Ser no Parmênides e no Sofista, naquele que é considerado o seu último escrito, As Leis, neste a justiça não se pauta mais no pressuposto da possibilidade definitiva da Metexis entre formas e coisas, mas na sua delimitação enquanto critério diretivo dos esforços humanos visando aproximação possível do conhecimento e o Bem e governo legislativo da cidade. Platão. Leis, 1980 b, 624a, p. 19.

${ }^{3}$ Dentre outras interpretações pode ser mencionada aqui a Theory of neural Group Selection de Gerald Edelman, também conhecida como "darwinismo neural" (Edelman, 2004, p. 32), que oferece uma explicação biológica para a origem da mente a partir da categorização perceptiva do sistema nervoso em sua relação adaptativa a um mundo não compreendido. Para Edelman, a estrutura neural de um organismo não é determinada exclusivamente pelo seu repertório genético, mas também pelo contato com o mundo e os estímulos que este gera uma interação dinâmica das interações celulares (sinapses), tal como elas ocorrem em determinadas áreas do sistema nervoso, a partir de modificações de intensidade entre as sinapses decorrentes do comportamento e da experiência com o meio. Desse modo, a consciência primária emerge evolutivamente a través de novos circuitos de mediação em áreas posteriores do cérebro, relacionadas com a categorização perceptiva, que são dinamicamente acionadas. Posicionamentos como o de Edelman indicam dados relevantes no sentido de indicar estruturas neurais dinâmicas a partir da interrelação com o mundo.

${ }^{4}$ No sentido como o que Searle indica em sua ideia de sistemas causalmente emergentes, que esclarece a consciência por intermédio de interações causais presumidas, mas que nega a possibilidade daquela ser deduzida "a partir da mera estrutura física dos neurônios, sem alguma descrição adicional das relações causais entre eles" (Searle, 2006, p. 162), dado que "as características de primeira pessoa são diferentes das de terceira pessoa" (Idem, p. 170) e, assim, a consciência "está excluída de um determinado modelo de redução" (Idem, p. 177), como o empregado nas ciências.

${ }^{5}$ A esse respeito escreve Bickhard: "The natural emergence of such normative phenomena as normative function and representation forms the foundation for multiple further normative emergences, such as memory, learning, social realities, language, and so on, up to and including ethics and morality (...) In itself, however, the model of the emergence of foundational normativity, in the form of normative function, constitutes a claim that normativity in general is emergently natural" (2010, p. 27-8). 
6 Joshua Gert, argumenta que mesmo quando a racionalidade busca fatos para justificar um princípio teórico, esse procedimento agrega a crença como consequência no seu processo dedutivo, mesmo quando este remete a consequências não desejadas (2004, p.7). O que, para o autor, implica que a racionalidade teórica normativa não pode ser associada a uma noção de pura racionalidade, mas sim a uma racionalidade funcional, que o autor chama de subjetiva, mas que não deve ser vista como irracional, por estar conectada a um funcionamento mental (mental functioning) e se diferenciar de uma racionalidade objetiva, devido esta não se deixar restringir por um limite prático (Ibid, p. 27).

7 Como fica patente na diferenciação enunciativa entre as senteças "O que é o caso?" e "Qual deveria ser o caso". Conf. Wedgwood, 2007, 28.

8 Pautada na compreensão da especificidade de dados referenciais, dos métodos de obtenção destes, de seus critérios de justificação e ainda na compreensão da existência de noções ou termos que não podem ser reduzidos a termos decorrentes de aplicação dos métodos hipotéticos das ciências sem perdas cognitivas ou semânticas, mas que há uma diferença ontológica entre eles, que impossibilita que sejam considerados segundo os mesmos pressupostos. Tal como, por exemplo, a diferença entre objetos identificáveis por meio da experiência espaço-temporal e padrões valorativos. A respeito conferir Quintanilla, 2013, p. 34.

${ }^{9}$ Kant, 1974. "Die Gegenständen müssen sich nach dem Erkenntnis richten" B XVI.

10 Schopenhauer, WWV I/MV I § 24, p. 182 . Nietzsche, Morgenröte $\S 116$, KSA 3, p. 109. Fröhliche Wissenschaft § 7, KSA 3, p. 421.

${ }^{11}$ Aspecto que é retomado na Conferência sobre ética na distinção entre juízo de valor absoluto e juízo de valor relativo. Considerando os segundos como meros enunciados de fatos, Wittgenstein afirma: "Now what I wish to contend is, that I though all judgements of relative value can be shown to be mere statements of facts, no statement of fact can ever be, or imply, a judgement of absolute value." (2014, p. 45) Juízos de valor, portanto, não enunciam estados existentes, mas estados mentais que avaliam fatos e que, portanto, não podem ser compreendidos como enunciando características efetivas de algo.

12 Esta, por exemplo, é a posição defendida Por Donald Davidson, para quem a ideia de correção valorativa se baseia em poderosa intuição, advinda de pensamentos intuitivos e sem proteção (unguarded), aos quais, apesar disso, nós tendemos a tentar conferir validade objetiva. Davidson Problems of Rationality, 2006 , p. 39.

13 Gert utiliza a distinção feita por Allan Gibbard entre racionalidade objetiva e racionalidade subjetiva para refletir sobre esta questão. A primeira pressuporia uma ampla ou completa interpretação de dados objetivos relativos às valorações, a segunda envolveria aspectos valorativos que extrapolam a subjetividade.

14 Que podem inclusive ser interpretadas como ato irracional. Gent, Bernard. Moratity: its Nature and justification. Oxford, 2005, p. 30. 
${ }^{15}$ Fodor, J. afirma: "there is nothing in the 'evolutionary,' or the 'biological,' or the 'scientific' worldview that shows, or even suggests, that the proper function of cognition is other than the fixation of true beliefs" (2000, p 68).

16 Neste sentido pode-se mencionar a interpretação de Wilfrid Sellars, acerca do raciocínio prático de nossas generalizações empíricas e de sua relação com leis científicas e princípios lógicos, para quem a causalidade é redutível, todavia não a uma instância unicamente lógica, mas também a uma estrutura conceitual prática expressa basicamente pela estrutura:

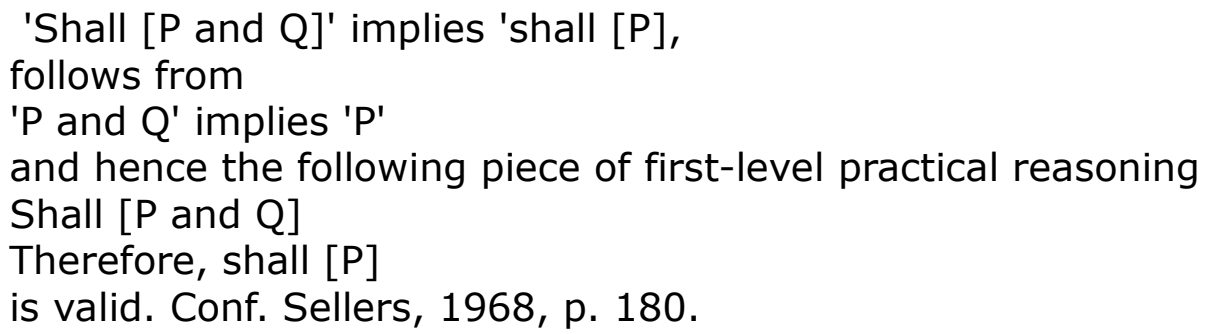

17 Maria Frapolli denomina tal perspectiva de "Truth-conditional Semantics", segundo a qual, "Terms acquire their meanings because they are connected one way or another to extralinguistic entities; sentences represent states-of-affairs, they are models of possible situations." (Frapolli, 2010, p. 235). Este ponto de vista possibilita que se argumente em favor de uma concepção representativa do signo submetida não a processos de determinação, mas de interpretação, aproximada, portanto, da concepção wittgensteiniana de uma semântica de verdade condicional, para a qual significados decorrem do seu uso e não de referencialidades objetivas. Thomas Nagel (1998, p. 119) se coloca de acordo com este aspecto, obstante a sua divergência com respeito à avaliação das potencialidades da compreensão evolucionista da racionalidade.

18 Gibbard propõe algo neste sentido quando indica o aspecto normativo da conceituação e do significado, que ele diferencia da discussão acerca das propriedades do significado, objeto das ciências naturais $(2013$, p, 28) pois, para ele, a discussão acerca do que seriam propriedades não pode ser tratada em uma perspectiva referencial, pois esta requer de uma teoria substantiva (substantive theory) do uso das palavras e frases, que implicaria uma consideração normativa do significado, interpretado por ele como disposicional (dispositional) (Idem, p. 37).

19 Gibbard, acompanhando Paul Hornwich, menciona uma necessidade primitiva de coerência, que ele associa com a pretensão semântica de significado (2013, p, 115 ), indicando porém que esta questão não pode ser respondida unicamente pela ótica naturalista, que não considera para ele a questão do significado a partir do uso linguístico dos termos, assim como da nossa limitada capacidade de pensar temas acuradamente, o que seria responsável por leis e obrigações (Oughts) ideais concernentes ao significado. Assim a afirmação "a neve é branca", pressuporia que algo é branco, por conseguinte, que a brancura existe (2013, p. 116). Desse modo, o autor discorda que nossas crenças significativas decorram todas de aceitação de sentenças, mas também da própria estrutura linguística (2013, p. 118). 
20 Dirigindo esta questão para o âmbito da normatividade e tomando esta como resultado de generalizações, é possível mencionar Christine Korsgaard, que em Sourses of Normativity (1996) reflete a respeito da origem da autoridade dos conceitos éticos, mais especificamente de como a moralidade se tornou normativa (p.10), a partir do ponto de vista segundo o qual a normatividade é um aspecto humano não contornável e presumivelmente "a real force in Human Live" (p. 13). A autora é aqui mencionada por discordar de uma abordagem evolucionista da moralidade, devido compreender como restritiva a proposição segundo a qual a ação moral poderia ser esclarecida instintivamente. Korsgaard, todavia, faz uma apropriação bastante delimitada do impulso de preservação, ao diferenciá-lo de questões valorativas (We might now question whether the evolutionary theory does provide an adequate explanation of moral motivation after all), pois parece conceber respostas instintivas por meio de uma noção de causalidade bastante simplória e centrada em uma concepção de individualidade que não é componente intrínseco do instinto. Pois, para ela, se na natureza a preservação individual ocorre, ela está também ligada à preservação da espécie e ambas parecem ser indissociáveis. Mas, e esse parece ser o ponto central da fragilidade de sua argumentação de Korsgaard, o instinto não "pensa" a espécie, ele parece estar muito mais ligado à percepção da importância do grupo que compõe para a sobrevivência. Desse modo, questões valorativas específicas, como a mencionada pela autora (o dilema de ajudar ou não judeus ameaçados de morte por nazistas, cogitando com isso que estes também fazem parte da espécie) nos parece, como a própria autora menciona, "fanciful" (p. 15), pois insere na discussão aspectos não primeiramente naturalistas, mas decisivamente valorativos. Ao considerar a questão moral como uma questão de primeira pessoa (The normative question is a first-person question that arises for the moral agent who must actually do what morality says), a autora insere no seu questionamento da teoria evolucionista uma perspectiva que muito provavelmente não possui bases naturais instintivas primordiais, mas apenas a posteriori, haja visto ser o intelecto humano, também decorrente da evolução orgânica do Homo sapiens (Maturana e Varela, 1987, p. 23), e que mesmo fazendo uso de identificações e generalizações, muito provavelmente não partiu de uma noção refletida ou teórica destas noções, ou seja, de noções definidas de identidade ou de subjetividade, que são intelectivas e resultantes de desdobramentos posteriores da capacidade simbólica e criadora da mente humana (Eugênio, 2013, p. 74). A valoração da normatividade desvinculada de bases naturais imediatas efetuada por Kosgaard parece deste modo desconhecer ou desconsiderar resultados constatáveis por pesquisas comportamentais comparativas. 


\section{Referências bibliográficas}

ABEL, Günter. Filosofia como signo e como interpretação. Tradução brasileira de Roberto Barros e Rogério Lopes. Campinas: Editora PHI, 2020.

ABEL, Günter. Abel in Dialog vol. 1. Berlin/New York: Walter de Gruyter, 2018.

ANGIONI, Lucas. Sobre a relação entre matéria e forma na constituição da essência sensível em Aristóteles. Campinas: Cadernos de História da Filosofia da ciência (UNICAMP), série 3, vol 7, n 2, 1997, p. 209 - 251.

CORRÊA, Nicholas Kluge. Incerteza moral e meta normatividade. In: Santos, Daniel. Alves, Eduardo e Oliveira, Gustavo Oliva de (Org.), XX semana acadêmica do PPG em Filosofia da PUCRS. Porto Alegre: Editora Fundação Fenix, 2020, p. 31-46.

DALL'AGNOL, Darlei. Neurociência cognitiva e epistemologia moral: sobre a irredutibilidade do saber ao conhecimento. ethic@, Florianópolis, vol. 19, n.1, p. 49-60. 2020.

FODOR, Jerry. The Mind doesn' $t$ work that Way. Massachussets: MIT Press, 2000.

GENT, Bernard. Moratity: its Nature and justification. Oxford, 2005.

BICKHARD, Mark $\mathrm{H}$. Is Normativity natural? In Milkovski and Kaminski (Org): Beyond description naturalism and Normativity. London: College publications, 2010.

BRASSINGTON, Iain. Truth and Normativity. UK: Ashgate publishing Company, 2007.

CHOMSKY, Noan. Language and Mind. Edinburg: Cambridge University Press, 2006.

COOP, David. Morality, Normativity \& Society. Oxford, 2001.

DAMÁSIO, António. O mistério da consciência. Do corpo e das emoções ao conhecimento. Tradução brasileira de Laura Teixeira Motta. São Paulo: Companhia das Letras, 2000.

DAVIDSON, Donald. Problems of Rationality. Oxford: 2006.

EDELMAN, Gerald. Wider than the Sky. The Phenomenal Gift of Consciousness. USA: Yale University Press, 2004. 
EDELMAN, Gerald. Seconde Nature. Brain Science and human Knowledge. USA: Yale University Press, 2006.

EUGÊNIO, Tiago José Benedito. Um olhar evolucionista para os mecanismos cognitivos associados às trocas sociais. Brasília: Psicologia: Teoria e pesquisa, 2013, vol. 19, n1, pp. 71-78.

FRÁPOLLI, Maria j. Naturalizing Logic. The inference maker View. In Milkovski and Kaminski (Org): Beyond description naturalism and Normativity. London: College publications, 2010, pp. 226-242.

FUMERTON, Richard. Episthemology. USA/UK/Austrália: Blackwell Publishing, 2006.

GERT, Joshua. Brute Rationality. Normative and human Action. New York: Cambridge university Press, 2006.

GIBBARD, Allan. Meaning and Normativity. UK: Oxford University Press, 2013.

HASELTON et al. Adaptative Rationality: An evolutionary perspective on cognitive Bias. Social Cognition, vol. 27, n. 5, 2009. USA: Chapman University, pp. 735-763.

JOHNSTON, PAUL. The Contraditions of modern moral Philosophie. Ethics after Wittgenstein. New York/London: Routledge, 1999.

KANT, Immanuel. Kritik der reinen Vernunft. Frankfurt am Main: Surkamp, 1974.

KIESEWETTER, Benjamin. The Normativity os Rationality. UK: Oxford University Press, 2019.

KORSGAARD, Christine. Sourses of Normativity. Oxford, 1996.

LORENZ, Konrad. Die Rückseite des Spiegels. München: DTV, 1993.

MATURANA, Humberto R. e VARELA, Francisco. The Tree of Knowledge. The biological Roots of Human Understanding. Boston: Shambala Publications, 1987.

NAGEL, Thomas. A Última palavra. Tradução brasileira de Carlos Felipe Moisés. São Paulo: UNESP, 1998.

NIETZSCHE, Friedrich Wilhelm. Sämtliche Werke. Kritische Studienausgabe (KSA). Ed. G. Colli e M. Montinari. München, de Gruyter/DTV, 1980. 
NOZICK, Robert. The Nature of Rationality. New Jersey: Princeton university Press, 1993.

PLATÃO. República. In: Diálogos. Trad. Carlos Alberto Nunes. Belém: Universidade Federal do Pará, 1980a.

PLATÃo. Leis e Epinomis. In: Diálogos. Trad. Carlos Alberto Nunes. Belém: Universidade Federal do Pará, 1980b.

PFORDTEN, Dietmar von der. Validity in positive Law: A mere Summary Concept. In: Westerman/Hage/kinster and Mackor (Org). Legal Validity and soft Law. Schwitzerland: Springer Verlag, 2018, pp. 1-18.

PÖLTNER, Günter. Evolutionäre Erkenntnisstheorie. Stuttgart/Berlin/Köln: Kohlhammer $\mathrm{GmbH}, 1993$.

QUINE, Willard van Orman. Natural Kinds. In: Ontological relativity and other Essays. Columbia University Press, 1969, p. 114-138.

QUINE, Willard van Orman. De um ponto de vista lógico. Tradução brasileira de Antônio Ianni Segatto. São Paulo: UNESP, 2011.

QUINTANILLA, Pablo. Naturalism and the Mind - The final Question. In: Alberto cordero/José Inácio Galparsoro (Org.). Reflections on Naturalism. Rotterdam: Sense Publishers, 2013, pp. 33-44.

SCHNEIDER, Hans Julius. Knowledge Form and Language Form. In: Günter Abel/James Conant (org): Rethinking Epistemologie, vol I. Berlin/Boston: Walter de Gruyter, 2012, pp. 135 - 152.

SEARLE, John. A redescoberta da mente. São Paulo: Martin Fontes, 2006.

SELLARS, Winfrid. Variations on Kantian Themes. London: Routledge \& Keagan Paul Ltda, 1968.

SCHOPENHAUER, Arthur. Werksausgabe. Zürich: Haffmans Verlag, 1987.

WITTGENSTEIN, Ludwig. Tractatus logico-philosophicus. Werkausgabe Band I. Frankfurt am main: Surkamp, 1984.

WITTGENSTEIN, Ludwig. Philosophische Untersuchungen. Werkausgabe Band I. Frankfurt am main: Surkamp, 1984.

WITTGENSTEIN, Ludwig. Lecture on Ethics. USA/UK: Wiley Blackwell, 2014. 
WEDGWOOD, Ralph. The Nature of Normativity. New York: Claredon Press, 2007.

WUKETITS, Franz M. Evolutionary Episthemologie and its Implications for Humankind. New York: State University Press, Albani, 1990.

Received/Recebido: $18 / 12 / 20$ Approved/Aprovado: 06/04/21 